http://dx.doi.org/10.12795/RAA.2011.i01.01

\title{
LOS PAPELES POSIBLES DE LA ANTROPOLOGÍA EN TIEMPOS DE GLOCALIZACIÓN*
}

\section{ISIDORO MORENO}

\section{Grupo de Investigación GEISA. Universidad de Sevilla}

\section{Resumen.}

El autor plantea las opciones actuales de la Antropología que se elabora en los sures (en los países del Sur y en los diversos sures existentes en el Norte) partiendo de la desnaturalización de las bases y paradigmas de la Modernidad sobre los que se han construido las ciencias sociales hegemónicas.

Tras un análisis de los pilares de la Modernidad y de su quiebra, y del continuum Modernidad-Progreso-Desarrollo-Globalización, se rechaza este paradigma y la sacralización actual de la lógica del Mercado, proponiéndose como alternativa el paradigma de la glocalización o doble dinámica globalización-localización. En el contexto de las diversas formas de relación global/local, se plantea avanzar en la construcción de una Antropología, no subalterna respecto a la que se reproduce en los centros de poder académico, que ponga de manifiesto los mecanismos estructurales y simbólicos de las desigualdades y se comprometa en la defensa de la diversidad cultural y los derechos colectivos.

\footnotetext{
*Una primera versión de este texto fue presentada por el autor en el Coloquio Internacional "Archipiélagos de la Antropología”, organizado en México DF por la Universidad Autónoma Metropolitana en noviembre de 2008.
} 
Palabras clave: Antropologías del Sur, Glocalización, Crítica de la Modernidad, Nuevos paradigmas, Descolonización.

\begin{abstract}
.
The author explains the current options for Anthropology which are drawn up in the souths (in the countries of the South and in the several souths within the North ) starting from the premise of the denaturalization of the grounds and paradigms of Modernity, on which hegemonic social sciences have been constructed.

After an analysis of the pillars of Modernity and its breakdown, and of the continuum Modernity-Progress-Development-Globalization, this paradigm and the current sacralization of the Market logic are rejected, proposing the paradigm of glocalization or globalization-localization double dynamic as an alternative. In the context of the diverse forms of global/local relations, the author suggests to advance in the construction of an Anthropology, not subordinated to that re-produced in the centers of academic power, which highlights the structural and symbolic mechanisms of inequality, and which undertakes the defense of cultural diversity and collective rights.
\end{abstract}

Keywords: Anthropologies of the South, Glocalization, Critique of Modernity, New Paradigms, Decolonization.

\title{
1. SOBRE EL SUR Y LOS SURES EN LA ANTROPOLOGÍA ACTUAL.
}

Conviene comenzar este ensayo, en el primer número de esta nueva Revista Andaluza de Antropología, manifestando mi posicionamiento en el contexto actual de la disciplina. Aunque en mi pasaporte puede leerse "Unión Europea. España”, no me considero un ciudadano del Norte en su sentido económico-político ni ideológico por un doble motivo: porque soy andaluz - y Andalucía es un país cuya historia y cultura no responde al modelo general europeo- y porque pertenezco a una Antropología periférica, todavía hoy en gran parte colonizada y considerada subalterna tanto por las instancias centrales del poder académico como por una parte significativa de quienes la practican en el Estado Español y en la propia Andalucía aceptando la dependencia de aquellas. 
Sobre lo primero, no poco he escrito en mi ya larga trayectoria docente e investigadora', casi siempre a contracorriente de las tendencias políticas y universitarias dominantes, y no sería adecuado repetir aquí lo ya argumentado. Respecto a lo segundo, baste recordar que el Mediterráneo europeo, junto a las sociedades campesinas de América Indoafrolatina², sustituyó a partir de los años cuarenta del siglo pasado como objeto

1. Entre otras publicaciones del autor sobre Andalucía y su identidad cultural, histórica y política pueden verse Moreno, Isidoro: "Primer descubrimiento consciente de la identidad andaluza (1868-1890)"; "La nueva búsqueda de la identidad perdida (1910-1936)" y "Hacia la generalización de la conciencia de identidad (1936-1981)”, en A. Domínguez Ortiz (director): Historia de Andalucía, vol. VIII, pp. 233-298. Madrid-Barcelona, CUPSA-Planeta, 1981; "La identidad andaluza: pasado y presente. (Una aproximación antropológica)", en VV.AA.: Andalucía, pp. 253-285. Editoriales Andaluzas Unidas, Sevilla, 1986; "Etnicidad, conciencia de etnicidad y movimientos nacionalistas: aproximación al caso andaluz". Revista de Estudios Andaluces, 5 (1986), pp. 13-38; Andalucía: Identidad y Cultura. (Estudios de Antropología Andaluza). Ed. Ágora, Málaga, 1993; "La identidad andaluza y el Estado Español", en R. Ávila Palafox y T. Calvo Buezas (comp.): Identidades, Nacionalismos y Regiones, pp. 73-109. Universidad de Guadalajara (México) y Universidad Complutense de Madrid, 1993; "Andalucía en la encrucijada de un mundo en crisis". Revista de Estudios Regionales, 44 (1996) pp. 371-385; "La identidad de Andalucía", en Conocer Andalucía. Gran Enciclopedia andaluza del siglo XXI (G. Cano, director), vol. 6: Cultura Andaluza, pp. 12-59. Ed. Tartessos, Sevilla, 2000; "La identidad andaluza en el marco del Estado Español, la Unión Europea y la Globalización”, en G, Cano, J. Cazorla, I. Moreno y otros, La identidad del pueblo andaluz, pp. 155-172. Ed. Defensor del Pueblo Andaluz, Sevilla, 2001; La globalización y Andalucía. Entre el mercado y la identidad. Mergablum, Sevilla, 2002; "Cultura andaluza, patrimonio cultural y políticas de patrimonio". Demófilo. Revista de Cultura Tradicional, $3^{a}$ época ${ }^{\circ} 1$ (2002), pp. 71-87; “¿Del subdesarrollo a la postmodernidad? La sociedad andaluza y la llamada 'segunda modernización”, en J. Hurtado Sánchez (coord.) Sociología de 25 años de Autonomía, pp. 45-80. Consejería de Relaciones Institucionales, Junta de Andalucía, Sevilla, 2004; "La 'segunda modernización' de Andalucía: discursos y prácticas del neoliberalismo en una sociedad de la periferia del centro", en VVAA, La globalización y los derechos humanos, pp. 317-360. Talasa Ediciones y Asociación Pro Derechos Humanos de Andalucía, Madrid, 2004; "Visibilidad e invisibilidad de Andalucía en los estudios antropológicos sobre Andalucía", en Alberto Egea Fernández-Montesinos (coordinador), Dos siglos de imagen de Andalucía, pp. 59-76. Centro de Estudios Andaluces, Sevilla, 2006; y La identidad cultural de Andalucía. Aproximaciones, mixtificaciones, negacionismo y evidencias (Introducción y selección de textos). Centro de Estudios Andaluces, Consejería de la Presidencia, Sevilla, 2008.

2. Desde mis primeros años de universidad, todavía en la época de la dictadura, rechacé por colonialista el término Hispanoamérica, utilizando siempre el de América Latina. En aquel contexto, esto constituía una toma de posición político-ideológica antifranquista y de izquierda; pero más tarde, sobre todo a partir de mis reflexiones con ocasión de las conmemoraciones de 1992, decidí eliminar también de mi vocabulario esa expresión, sustituyéndola por la de América Indo-Afro-Latina. Considero que la visibilización en la terminología de los componentes indios y negros de las sociedades y culturas que siguen siendo denominadas latinoamericanas reflejando con ello sólo uno de sus tres componentes- es parte importante no sólo del necesario reconocimiento de la realidad sino también del imprescindible proceso de descolonización intelectual. Es una opción que tiene, sin duda, importantes implicaciones políticas. Ver, al respecto, Moreno, Isidoro: "América en la conciencia española: del IV al V Centenario". En Colloque International de l'AFSSAL: Les Enjeux de la memoire. L'Amerique Latine a la Croisse du Cinquieme Centenaire. Commemorer ou Rememorer? , pp. 1-25. AFSSAL, París, 1992; «América y el nacionalismo de estado español del IV al V Centenario». Revista de Estudios Regionales, 34 (1992), pp. 53 78; y "Europa mediterránea y América Indo-afro-latina: las miradas recíprocas", en I confini del Mediterraneo. Etnicità, nazione, religione tra Europa e América Latina, pp. 135-165. Centro Internazionale di studi sul religioso contemporaneo, Cittá di San Gimignano-Titivillus Edizioni, 2004. 
de estudio antropológico a los supuestos "pueblos primitivos" africanos, oceánicos y amerindios, siendo construido, desde los centros de poder académico euronorteamericanos, como la otredad cultural cercana (cómoda de investigar, además, en una época en que los movimientos de liberación habían acentuado su presencia en muchas otras partes del mundo). Ello, a pesar de la larga tradición de estudios propios, primero de Folk-lore y luego también de Antropología, existentes en la mayoría de los países europeos mediterráneos desde el siglo XIX ${ }^{3}$. Paradigma de la no consideración, por no decir del desprecio, a las producciones de los "nativos mediterráneos", incluidos los académicos, es el conocido libro de John Davis, que fue referencia durante muchos años para los mediterraneistas europeos y norteamericanos, en cuya bibliografía están referenciadas casi exclusivamente las obras publicadas en inglés (ninguna en español o italiano, por ejemplo) $)^{4}$.

El surgimiento o desarrollo, en la segunda mitad del siglo XX, de instituciones, estudios académicos e investigaciones en países mediterráneos, de América Indoafrolatina, africanos y asiáticos - que, en algunos casos, incluso han colocado a la Antropología en un lugar más central dentro de las ciencias sociales que en varios de los propios países del Norte - no ha tenido la repercusión que habría sido adecuada por un doble motivo: la situación de colonización intelectual en que se han creado y desarrollado buena parte de esas instituciones y estudios, y la escasa relación de las Antropologías del Sur entre sí. La colonización intelectual que sufren gran parte de las Antropologías "periféricas" por parte de las Antropologías "metropolitanas" - principalmente de las tendencias y escuelas hegemónicas en Estados Unidos, Inglaterra y, más secundariamente, Franciaresponde, principalmente, a la fetichización de modelos teóricos, categorías y temáticas surgidos en los centros de poder académico de dichos países y a su aceptación acrítica como universalmente válidos y exponentes del más alto nivel científico. Lo que

3. En el caso concreto de Andalucía y el Estado Español, además de los folkloristas decimonónicos —de muy diverso valor - hay que hacer notar la pronta creación de Sociedades de Antropología, como las de Madrid, Sevilla y otros lugares -la de Sevilla es de 1870- aunque a nivel universitario la disciplina no se introdujera por motivos claramente ideológico-políticos. Véanse, entre otros, Lisón Tolosana, C.: Antropología Social en España. Siglo XXI, Madrid, 1972; Moreno, I: "La Antropología en Andalucía. Desarrollo histórico y estado actual de las investigaciones". Ethnica, 1 (1971), pp. 107-144; Moreno, I.: "La investigación antropológica en España”, en A. Jiménez (ed.): Primera Reunión de Antropólogos Españoles, pp. 325-333, Sevilla, Publicaciones Universidad de Sevilla, 1975 y Prat i Carós, J.: Antropología y Etnología. Ed. Complutense, Madrid, 1992.

4. John Davis: People of the Mediterranean, Essay in comparative social anthropology. Routledge \& Kegan Paul. London, Henley y Boston, 1977. Hay traducción al español (sin notas ni bibliografía), Antropología de las Sociedades Mediterráneas. Anagrama, Barcelona, 1983. 
Edgardo Lander y otros colegas $s^{5}$ han denominado "la colonialidad del saber" consiste en la asimilación, por la mayoría de los antropólogos, sociólogos, politólogos y otros científicos sociales de Asia, África, América Indoafrolatina y el Mediterráneo, de unos saberes coloniales y eurocéntricos que naturalizan la subordinación de todas esos continentes y regiones al universalizar un único modelo de proceso histórico, el europeo u occidental, y unas únicas formas válidas de conocimiento, las de las ciencias sociales construidas en el Norte. Esta situación colonizada de gran parte de las Antropologías del Sur -y, en general, del conjunto de las ciencias sociales- constituye hoy el obstáculo fundamental para que el conocimiento antropológico se convierta, en muchos países, en una palanca que impulse las necesarias transformaciones sociales y la resistencia frente a la globalización mercantil totalitaria que amenaza con desintegrar las identidades de los pueblos.

La batalla, sin embargo, está planteada desde hace varias décadas. Ya en los años sesenta se señaló la estrecha relación histórica entre el surgimiento y expansión de la Antropología y los intereses del colonialismo. Las Declaraciones de Barbados fueron, a comienzos de la década siguiente, un hito en la denuncia de dicha relación y por la descolonización del conocimiento. A partir de aquí, un creciente número de antropólogos y colegas de otras disciplinas comenzaron a elaborar un difícil pero imprescindible conocimiento descolonizado cuya indudable calidad científica tuvo que ser reconocida incluso en algunos ámbitos del Norte. Nombres como los de Guillermo Bonfill, Alonso Quijano, Rodolfo Stavenhagen, Walter Mignolo, Arturo Escobar y algunos otros fueron o son muy importantes en la creación de unas ciencias sociales no colonizadas, cuestionadoras del paradigma de la modernidad occidental como modelo civilizatorio universal. Y otros jóvenes, y ya no tan jóvenes, antropólogos y antropólogas, tanto de América Indoafrolatina como de Asia, África y el Mediterráneo desarrollan hoy su actividad en esta línea, aunque no sin dificultades.

En contraste, en muchos ámbitos académicos del Sur -incluyendo en el Sur a los sures existentes en el Norte, específicamente los países del mediterráneo europeo: los que integran el Estado Español, Italia, Grecia y Portugal entre otros- ha continuado, e incluso se ha acentuado, la dependencia respecto a las antropologías centrales. Esto se refleja en el contenido de la formación que es considerada adecuada para los nuevos profesionales, en la obligatoriedad de publicar en revistas de prestigio - básicamente las que se publican en los centros de poder académico- como condición sine qua non para avanzar en la carrera académica; en el menosprecio de los temas calificados despectivamente como "locales", que en realidad no refieren tanto al territorio como a las cuestiones que se

5. E. Lander (ed.): La colonialidad del saber: eurocentrismo y ciencias sociales. Perspectivas latinoamericanas. CLACSO, Quito, 2005 [2000]. 
estudian, si son diferentes a aquellas que son definidas como importantes - a veces, simples modas - en los departamentos de las universidades del Norte; e incluso se llega, como ocurre hoy en España, a que las agencias gubernamentales de evaluación de los profesores universitarios penalicen el publicar en las instituciones donde se desarrolla la labor docente de estos o en editoriales de los lugares en los que se han realizado las investigaciones.

Es esta subordinación, esta verdadera colonización intelectual - como yo la llamé hace ya más de veinticinco años ${ }^{6}$ - que obliga a estar pendientes sólo de las producciones y tendencias que se generan en los centros del Norte, lo que provoca el profundo desconocimiento que sigue caracterizando, de forma predominante, a las relaciones entre los diferentes sures, constituyendo a estos como islas periféricas mal comunicadas entre sí y muy dependientes de sus respectivos nortes?

\section{ELPAPELDELA ANTROPOLOGÍA ENLANECESARIADESNATURALIZACIÓN DE LOS PARADIGMAS Y PILARES D ELA MODERNIDAD OCCIDENTAL.}

El modelo civilizatorio hoy dominante, mediante su naturalización como modelo universal al que han de acercarse todos los pueblos del mundo, sigue siendo el de la Modernidad. Las palabras-talismán que han rotulado sucesivamente el proceso han cambiado: Progreso, Modernización, Desarrollo, Globalización, pero sus contenidos

6. Moreno, I: “La doble colonizació de l'antropología andalusa i perspectives de futur". Quaderns de l' Institut Catalá d’Antropología, 5 (1984), pp. 69-84; “La Antropología Cultural en Andalucía: estado actual y perspectivas de futuro", en VV.AA.: Antropología Cultural de Andalucía, pp. 93-107. Consejería de Cultura de la Junta de Andalucía, Sevilla, 1984; y “Fieldwork in Southern Europe and Scientific Colonization: the case of Andalusia”, en 13th European Congress for Rural Sociology, Abstract, pp. 196-198. Braga (Portugal), 1986. La polémica suscitada por el debate de mi ponencia en el Congreso de Braga, donde había numerosos antropólogos norteamericanos y de otros países anglosajones, fue de cierta envergadura y todavía varios años después tenía presencia en las páginas de revistas antropológicas. Así, en el no 3 (1992) de Antropología — publicada en Madrid—, con artículos de David Greenwood, con el significativo título de "Las antropologías de España: una propuesta de colaboración” y de varios destacados antropólogos/as de diversas nacionalidades de España. En 1990, el antropólogo catalán Joseph Llobera, afincado en Gran Bretaña, publicó un libro, La identidad de la antropología, (Anagrama, Barcelona, 1990) en la misma línea, donde afirmaba el "imperialismo cultural del Norte" y planteaba propuestas para avanzar hacia un mayor equilibrio en las relaciones entre los antropólogos del Norte y los de la periferia, incluyendo en esta a los antropólogos del Mediterráneo europeo.

7. No obstante, desde hace unos años existen importantes intentos de establecer de forma permanente relaciones horizontales en red, como lo refleja la creación de la RAM-WAM (Red de Antropologías del MundoWorld Anthropologies Network), en cuya web ( $\underline{\text { www.ram-wam.net) }}$ se han publicado interesantes textos sobre la situación de las Antropologías en diversos lugares del mundo, entre ellos el libro editado en 2006 por Gustavo Lins Ribeiro y Arturo Escobar, World Anthropologies.Disciplinary Transformations within Systems of Power. London, Berg Publishers. Más recientemente, la celebración, en 2008, del Congreso "Archipiélagos de la Antropología", organizado por la Universidad Autónoma Metropolitana de México, supuso también un paso importante para la creación de redes mediante acuerdos multilaterales entre universidades. 
son básicamente equivalentes o están estrechamente relacionados. Fue la Ilustración la que construyó las categorías de Progreso y de Modernidad, al menos en sus elementos fundamentales. Fue el pensamiento ilustrado, en lucha contra "las ideas supersticiosas de la religión" y reclamándose como respondiendo solamente a la luz de la Razón, el que naturalizó y afirmó el carácter universal de la sociedad liberal — cuyo único sujeto es el individuo- y de su modelo civilizatorio, al que deberían aspirar todas las sociedades y al que estas habrían de ser conducidas, incluso de forma coactiva si se resistieran a hacerlo por sí mismas.

La consideración desde las tradición judeo-cristiana de la diversidad cultural como algo negativo - como un castigo divino por los pecados de los hombres, según el mito de Babel - no sólo siguió vigente cuando el pensamiento ilustrado sustituyó al pensamiento religioso en la centralidad del ámbito ideológico, sino que se reforzó adoptando ahora una forma laica con no menos terribles consecuencias. En nombre de la Razón, que se convierte ahora en el nuevo Absoluto Social, en el nuevo sacro que reemplaza a Dios, cuanto no se ajusta a la lógica de lo razonable, a sus leyes y cánones, está automáticamente descalificado y debe, por tanto, ser eliminado. Por ello, quienes no tienen, no son capaces de alcanzar, o rechazan esa racionalidad son considerados inferiores, menores de edad intelectual, o semihumanos que han de ser mantenidos bajo control. Los infieles y paganos que habían de ser cristianizados - los “otros" del mundo anterior organizado en torno al Absoluto religioso- pasan a ser ahora salvajes y bárbaros que necesitan ser civilizados. En uno y otro caso, el llevarles "la verdad del evangelio" o "la luz de la razón" son justificaciones ideológicas equivalentes que legitiman la dominación política, el expolio económico y la destrucción cultural. E igualmente, se reconstruyen también los "otros internos": las mujeres no son ahora inferiores por designio divino - ¡fuera supersticiones! - sino porque están limitadas por la Naturaleza debido a sus (supuestas) características orgánicas y psicológicas. Y los niños, los “incultos” (?), los definidos como inmaduros psíquicos y cuantos no respondan al modelo de la racionalidad y la normalidad son construidos, asimismo, como "otros internos". La gran trampa que esconde, sin embargo, el mito de la Razón es que esta no es otra cosa que la naturalización de la lógica y los intereses de los varones blancos, europeos, adultos y burgueses, que son quienes tuvieron el poder de definirla convirtiéndose en su única referencia?.

8. Moreno, I.: “PProceso de secularización o pluralidad de sacralidades en el mundo contemporáneo?”, en A. Nesti (ed.): Potenza e Impotenza della Memoria. Scritti in onore di Vittorio Dini, pp. 170-184. Tibergraph Ed., Roma, 1998 [1993]; "Religión, Estado y Mercado: los sacros de nuestro tiempo", en C. V. Zambrano (ed.): Confesionalidad y Política. Confrontaciones multiculturales por el monopolio religioso, pp. 35-52. Universidad Nacional de Colombia, Bogotá, 2002 y “La trinidad sagrada de nuestro tiempo: mercado, estado y religión”. Revista Española de Antropología Americana no 33, pp. 13-26. Madrid, 2003.

9. Moreno, I.: o.c, 2002 y 2003. 
Por otra parte, como nos recuerda, entre otros, el citado Lander, la Ilustración realizó múltiples particiones del mundo de lo real, mediante la segmentación del conocimiento en campos separados que se adjudicaron a disciplinas científicas especializadas, con el objetivo de conseguir un conocimiento definido como objetivo (des-subjetivizado) y universal, cuando en realidad se trataba de conocimiento - a veces pseudoconocimientodescorporeizado (basado en el individuo como abstracción) y descontextualizado. Así, la Economía, la Sociología y la Ciencia Política construyeron lo económico, lo social y lo político como campos específicos y diferentes de la realidad, como ámbitos pre-sociales, y el modelo eurocéntrico - de experiencia histórica, de valores culturales y de objetivos sociales - fue convertido en el modelo universalista excluyente y en la encarnación del espíritu hegeliano de la Historia. Por su parte, la Antropología habría de dedicarse al estudio de los "otros externos" y la Psicología a estudiar las anomalías de los "otros internos ${ }^{10}$ ". En estos dos últimos casos, se trataba de estudiar la anormalidad —cultural o psíquica - definida desde el modelo de la normalidad naturalizada que encarnaban la civilización occidental, el género masculino, la raza blanca, el adulto social y la propiedad privada como pilar central de la sociedad.

Como recordaba hace unos años Jürgen Habermas, basándose en Max Weber, el proyecto de Modernidad tenía como una de sus finalidades la construcción, a partir de la racionalidad, de una esfera cognoscitiva-instrumental, una esfera moral-práctica y una esfera estético-expresiva, regulada cada una de ellas por su propia lógica y puesta en manos de los respectivos expertos especialistas, lo que llevaría a desarrollar una ciencia objetiva, una moral universal y un ámbito autónomo del arte. Para los más entusiastas ilustrados, esto, junto con el progreso de la ciencia y la tecnología, habría de llevar no sólo al control y utilización sin límites de las fuerzas y recursos de la naturaleza sino también al progreso de la justicia y la moral e incluso a la felicidad de los seres humanos ${ }^{11}$.

El triunfo de la lógica de la Razón, presentada como liberadora de las ataduras de las creencias irracionales sacralizadas —o sea, de la religión-, supuso la entrada en la Modernidad, entendida como una nueva fase en la historia, incluso como el comienzo de la historia de la verdadera humanidad, ya que suponía, al decir de Kant, "la salida

10. Lander, E.: o.c., pp.14-23.

11. Habermas realiza una inteligente crítica de varios de los componentes del proyecto de Modernidad pero no extrae de ella sus últimas consecuencias. Para él, dicho proyecto está "incompleto", ha derivado hacia "un distanciamiento entre la cultura de los expertos y la del público en general", pero sin embargo "debemos asirnos a las intenciones de la Ilustración" (Habermas, J.: "La modernidad, un proyecto incompleto", en Hal Foster y otros, La Posmodernidad, pp.19-36. Kairós, 1985, pp. 19-36). Este empeño en continuar defendiendo las bases ilustradas de la Modernidad, acudiendo a las intenciones y no a su contenido y puesta en práctica, responde, en mi opinión, a que nuestro sociólogo no encuentra otra alternativa a la Modernidad que la postulada por postmodernos y premodernos. Y precisamente no la encuentra porque su crítica no llega a los fundamentos del proyecto sino que se centra en algunos de sus desarrollos. 
del hombre de la minoría de edad" (en realidad, se afirmaba el modelo humano como equivalente a varón-blanco-adulto-propietario). Todo, desde entonces, vino a ser definido como moderno o pre-moderno, según respondiera o no al despliegue de la lógica de la Razón. Las dicotomías elaboradas a partir de aquí por las ciencias sociales: solidaridad orgánica versus solidaridad mecánica, gesselschaft versus gemeinschaft, civilizados/salvajes, folk/urbano y tantas otras responden a este rompimiento por el que la religión y los vínculos de sangre eran sustituidos por la Razón y la decisión libre.

Es imprescindible, para poder dibujar las limitaciones del pensamiento ilustrado y, sobre todo, sus consecuencias hasta el presente, explicitar, aún a riesgo de ser esquemático, cuáles fueron las bases o pilares del modelo general de Modernidad que dicho pensamiento fue elaborando a lo largo del siglo XVIII y que se impuso, naturalizándose y a la vez sacralizándose, primero en Europa y los Estados Unidos y luego en otras partes del mundo durante los siglos XIX y XX a través de sus dos variantes enfrentadas pero que en realidad no eran sino ramas de un mismo tronco: el liberalismo y el socialismo marxista ${ }^{12}$.

El primero y central de estos pilares fue la firme creencia en que el avance del conocimiento objetivo - de la Ciencia - y su aplicación mediante la tecnología lograría un crecimiento sin límites de la riqueza, al abrir cada vez más ámbitos de la Naturaleza a la explotación humana, cada vez más eficiente. Ello posibilitaría un crecimiento económico indefinido que traería consigo un avance correlativo en los planos social y moral. Fue en esta creencia en la que se basaron tanto la idea evolucionista de Progreso, edificada sobre la fe en $E l$ hombre, destinado a dominar la naturaleza con el único límite del grado de conocimiento científico y de desarrollo tecnológico existentes en cada época, como el concepto marxista de desarrollo de las fuerzas productivas, que podrían crecer indefinidamente si se lograba romper el obstáculo representado, también en cada época, por las relaciones sociales de producción dominantes, que serían su único freno estructural. Las diversas elaboraciones teóricas y sus correspondientes concreciones en proyectos políticos en la tradición liberal-burguesa y en la marxista-socialista —opuestas, sin duda, en importantes aspectos y utilizaciones - responden, en realidad, a esta misma raíz ideológica, asentada en un optimismo desbordado - o, mejor, en una prepotencia ciega - respecto a las posibilidades de las capacidades humanas para la explotación de la naturaleza sin otros límites que los representados, respectivamente, por la insuficiencia del conocimiento o las supersticiones y por las estructuras sociales que debían ser transformadas. Ninguna fuerza ni constricción exterior a lo humano (a su inteligencia y/o a las estructuras

12. Moreno, I.: "La crisis mundial actual y la quiebra de los modelos civilizatorios occidentales", en Memorie e identità: prospettive nei percorsi del mutamento. Quaderni della Fondazione, 4, pp. 145-149. Courmayeur, Valle d’Aosta, 1997; “Quiebra de los modelos de Modernidad, Globalización e Identidades colectivas”, en Alcina, J. y M. Calés (eds.), Hacia una ideología para el siglo XXI, pp. 102-131. Akal, Madrid, 2000. 
sociales construidas por los humanos), natural ni sobrenatural, podría impedir el avance indefinido del Progreso, apoyado en la ciencia y la tecnología. Que los beneficios de dicho progreso estuvieran destinados a favorecer a una minoría social o fueran socializados en provecho de la mayoría señala la diferencia principal, en el plano ético y político, entre los dos discursos ideológicos que estamos considerando; pero ello no invalida el hecho de que los planteamientos de fondo de ambos tienen una fuente común.

El segundo pilar de la Modernidad y, por tanto, también de sus dos versiones, lo constituye la creencia en que su avance tenía que producir, obligadamente, la extensión de la racionalidad en todos los ámbitos: la Razón gobernaría todas las decisiones individuales y colectivas, cada vez más libres de irracionalismos, de falsas percepciones de la realidad y de fantasmas metafísicos o religiosos. La secularización, el desencantamiento del mundo (en la famosa expresión de Max Weber) o el ateísmo construirían ineludiblemente una sociedad desacralizada, regida solamente por la lógica racionalista.

El avance de la homogeneización cultural sería el tercer pilar del proceso modernizador. De forma explícita y directa, o de modo más indirecto pero también indudable, las distintas teorías e ideologías de la Modernidad han afirmado como algo no sólo inexcusable sino también globalmente positivo el avance hacia un único modelo cultural. Y ello, a pesar de las consecuencias negativas que este avance pudiera producir en contextos concretos. Fuese lograda por medio de "presión civilizatoria" o por "aculturación" —eufemismos que han enmascarado durante mucho tiempo las situaciones de dominación colonialista y neocolonialista-, o a través de la creación revolucionaria del "hombre nuevo", la homogeneización cultural formaría parte esencial de la unificación del mundo y de la construcción de una única sociedad humana, que vendría a superar la maldición bíblica de Babel —explicación mítica, pero profundamente interiorizada y ahora racionalizada, de la diversidad cultural y la pluralidad lingüística entendidas como maldición y castigo-El cuarto y último pilar de la modernidad ha consistido en la afirmación de la existencia de un único motor histórico del cambio social. En el modelo liberal-burgués, este no es otro que el individuo - no olvidemos que siempre entendido como varón blanco, adulto y propietario-, en continua lucha competitiva con los otros individuos e incluso consigo mismo, por la superación. En el modelo socialista-marxista, este motor único lo es la clase social: en cada época histórica aquella clase que representa "el sentido de la historia", en permanente lucha, abierta o latente pero vigente siempre, con su clase antagónica. No había duda alguna que bajo el modo de producción capitalista esta clase era la obrera - por supuesto, también formada por varones blancos adultos, aunque esto no se explicitara casi nunca abiertamente-. Así, el individuo, en un caso, y la clase, con su vanguardia el partido, en el otro, han sido considerados, respectivamente, en las sociedades que respondían a uno y otro modelo, como los únicos sujetos sociales y, por ello, también como los únicos titulares de derechos. La exaltación de los valores 
individualistas en el modelo liberal, y la reducción de los individuos a su dimensión de clase, con la consiguiente reificación de esta, en el socialista, fueron las consecuencias directas del axioma. Lo que ha comportado que en los regímenes regidos por el liberalismo capitalista se haya producido la negación de los derechos de los colectivos sociales y en aquellos que se reclamaron socialistas a la minimización de los derechos, e incluso a la descalificación de las aspiraciones, de cada ser humano concreto.

\section{LAQUIEBRA DELOS PILARES DELA MODERNIDADY YUSCONSECUENCIAS.}

Los dos modelos ideológico-políticos de la Modernidad, construidos a partir del pensamiento ilustrado y extendidos o impuestos desde Europa a todas las otras regiones del mundo, han supuesto en los últimos doscientos años las dos vías, presentadas como opuestas y únicas, para entender el mundo y tratar de perpetuarlo - en un caso- o de transformarlo - en el otro-. Su actual quiebra, espectacular en el caso del rápido desmoronamiento de las sociedades del llamado "socialismo real" y no menos sorprendente, para muchos, en el caso de la actual crisis capitalista, responde fundamentalmente al hecho constatable de que nuestras sociedades actuales no reflejan, en sus dimensiones y ámbitos fundamentales, lo que sería esperable desde los análisis, afirmaciones y predicciones realizados a partir de los paradigmas y pilares de la Modernidad contenidos en dichos modelos. Ello es así porque se han mostrado muy poco sólidos los cuatro pilares o ejes que acabamos de describir, los cuales constituían el núcleo duro del paradigma de la Modernidad. No es necesario una mirada demasiado profunda a nuestro mundo actual para constatar el hecho cierto de que estos, que fueron el cimiento común para las dos grandes construcciones teóricas en pugna, han quebrado totalmente $\mathrm{o}$, al menos, han mostrado sus graves limitaciones para construir sobre ellos modelos de organización sociopolítica sólidos y positivos para el conjunto de la humanidad ${ }^{13}$.

El primero y más central de dichos pilares se ha venido abajo ante la evidencia, hoy incontestable, de que existen límites objetivos para el crecimiento indefinido de la explotación de los recursos naturales, incluidos los energéticos. Límites y umbrales que son exteriores al grado de conocimiento que poseamos, e independientes también de las estructuras sociales sobre las que organicemos la sociedad. Límites que tienen que ver con el hecho de que, lejos de ser reyes de la creación - como defendía la tradición judeo-cristiana- o materia inteligente separada de toda la demás materia, viva o inerte, y destinada a dominar esta — como planteaba la tradición marxista-, los seres

13. Moreno, I.: “Quiebra de los modelos de Modernidad, Globalización e Identidades colectivas”. Revista Chilena de Temas Sociológicos, 4-5, 1999, pp. 167-204. También en José Alcina Franch y Marisa Calés Bourdet (eds.): Hacia una ideología para el siglo XXI. La crisis civilizatoria de nuestro tiempo, pp. 102-131. Ed. Akal, Madrid, 2000 . 
humanos formamos parte de ecosistemas que pueden romperse como resultado de nuestras acciones, poniendo en grave peligro la propia existencia humana y la vida en el planeta. Límites cuyo traspaso acarrea consecuencias irreversibles, cuyos efectos estamos comenzando ya a sufrir: cambio climático, ampliación del agujero de ozono, aumento de la radioactividad, efecto invernadero, agotamiento de recursos... Aunque los poderes políticos de los estados, presionados por los intereses de las grandes corporaciones trasnacionales, apenas están reaccionando ante esta realidad, más allá de los discursos, y por ello el modelo consumista continúa siendo el único contemplado por las grandes masas de población - mantenerlo e incluso intensificarlo en los países del Norte y acceder a él desde el Sur constituyen hoy los objetivos centrales de la gran mayoría de los humanos-, no existe duda alguna de que no es posible que el Sur acceda a los estándares de vida predominantes actualmente en el Norte. Y no sólo por los obstáculos sociopolíticos que desde este se imponen para impedirlo, sino por imposibilidad ecológica. Como tampoco podrá por mucho tiempo mantenerse la dinámica del actual modo de vida de los países dichos "desarrollados", que hemos interiorizado como una conquista irreversible del progreso y que tiene como base un insostenible despilfarro de recursos que no es posible mantener, y mucho menos acrecentar, sin poner en serio riesgo el equilibrio ecológico a nivel mundial.

En este ámbito, el empeño por mantener invariables en el siglo XXI unas concepciones nacidas en el pensamiento europeo del XVIII, no sólo constituye un sinsentido histórico sino que es una verdadera agresión contra las generaciones futuras, que habrán de sufrir las consecuencias de la fiebre destructora de hoy, sólo explicable por el objetivo de la obtención del máximo beneficio para una ínfima minoría en el menor tiempo, no importa con qué consecuencias a medio y largo plazo. En cualquier caso, la explotación de los recursos está ya claro para todos que no puede responder a un proceso de intensificación indefinida: por esa vía no es posible acrecentar el bienestar sino acercarnos al borde de la barbarie social y de la catástrofe ecológica. No son ya viables, pues, ni defendibles, las ideologías que tenían su base en la fe y el optimismo ciego - fruto del desconocimiento - sobre el crecimiento indefinido de la riqueza como resultado de la explotación crecientemente intensiva de la naturaleza. Por eso es cada día más indispensable revisar el propio concepto de desarrollo, que no puede continuar siendo definido casi exclusivamente con parámetros económicos, la mayoría de las veces, además, unilaterales, y que no se transforma simplemente por añadir a dicho término otros que supuestamente cambian su naturaleza: sostenible, autosustentable, etc. Y, paralelamente, hoy se hace necesario también revisar el conjunto de valores que sustenta nuestra definición de la calidad de vida.

El segundo de los pilares sobre los que se construyeron los modelos e ideologías de la Modernidad era el proceso de racionalización y secularización que habría de acompañar 
de forma indisoluble y automática el avance de aquella. Respecto a esto, la realidad ha desautorizado el axioma, porque, lejos de existir hoy un mundo secularizado, por tanto libre de sacralizaciones y Absolutos sociales, lo que ha ocurrido es que, junto a un proceso de parcial laicismo - hoy confrontado por la ofensiva de los varios fundamentalismos de las religiones tradicionales y por la aparición de los llamados nuevos movimientos religiosos-, se han desarrollado diversos procesos de sacralización de ideas y valores laicos que eran centrales en el pensamiento ilustrado y el modelo de la Modernidad, que han venido a sustituir a las creencias y valores religiosos pero manteniendo la equivalencia de sus funciones y significados ${ }^{14}$.

Ya en el siglo XVIII, la mayoría de los enciclopedistas e ilustrados, a la vez que promovieron intelectualmente el laicismo, provocaron también, aunque apenas fueran conscientes de ello, la sacralización de la Razón y la definición del cartesianismo como única lógica admisible para los seres humanos plenos. De igual modo, la gran mayoría de los marxistas sacralizaron, un siglo más tarde, la Historia, al dar a esta una significación teleológica. En ambas ideologías, respectivamente, la racionalidad (burguesa) y el sentido de la Historia (con un único motor, la lucha de clases), sustituyeron a la religión en el lugar central del ámbito de lo sagrado. Simultáneamente a un proceso, por otra parte no completo y centrado sobre todo en occidente, de laicismo real, que reflejaba la pérdida de protagonismo central de lo religioso en la reproducción social, se dio una sacralización, apenas percibida pero no menos real, de lo racional-naturalizado y de lo históricosocietario, que pasaron a ser los ámbitos de las nuevas formas de trascendencia. Sobre estas nuevas formas de sacralidad se apoyaron, respectivamente, los estados basados en la ideología liberal-burguesa y en la marxista-socialista. A la íntima imbricación que existió durante milenios entre Estado y Religión - los dos Absolutos tradicionales-, sucedió, tras la caída del Ancient Regime, la estrecha imbricación entre Estado y Racionalidad y entre Estado e Historia (siempre entendida esta como teleología). A la alianza entre el trono y el altar, encarnados uno y otro en reyes y sacerdotes, sucedió la fusión entre estado burgués y lógica racionalista (en cuyo nombre hablan los ilustrados, los funcionarios burócratas, los científicos, los juristas, los economistas y los tecnócratas), y entre estado socialista, o supuestamente socialista, y sentido de la Historia, es decir entre el estado y el partido (a través de sus ideólogos y funcionarios) que representaba por definición a la clase que, también por definición, venía definida por la ideología marxista como

14. Moreno, I.: “PProgreso de secularización o pluralidad de sacralidades en el mundo contemporáneo?” En El mito y lo sagrado en el pensamiento y la literatura contemporáneos. Sevilla, 1993. También en "Secularización y persistencia de lo religioso en el Estado Español y América Latina”. XIII Congreso Internacional de Ciencias Antropológicas y Etnológicas, Resumen, p. 301; y "Modernidad, secularización y perduración de las fiestas religiosas populares: el caso de la semana santa sevillana”, en P. Antes, P. De Marco y A. Nesti (comp.): Identità europea e diversità nel mutamento contemporáneo, pp. 353-375. Firenze, 1995 y La Globalización y Andalucía. Entre el Mercado y la Identidad. Mergablum, Sevilla, 2002. 
encarnación de dicho sentido ${ }^{15}$.

Desde los años ochenta del siglo XX, es ya el Mercado el sacro central dominante, con sus (supuestas) leyes incontrovertibles y sacralizadas que asumen el mismo papel, también incontrovertible y sagrado, que tuvieron o tienen, para los seguidores (en realidad, fieles) de los otros sacros la ley de Dios, las leyes de la Razón y las leyes de la Historia. Como todo sacro, el Mercado tiene sus mitos y ritos legitimadores, sus espacios sagrados, sus pontífices y sus expertos a los cuales se aplican denominaciones "modernas", laicas, pero que no por ello dejan de ser funcionarios de la sacralidad y mediadores entre esta y el común de los humanos.

La falsa equivalencia entre lo sagrado y lo religioso, por una parte, y entre lo secular y lo laico por otra, está en la base de una confusión que distorsiona por completo los análisis. Una brillante frase al respecto del escritor andaluz Antonio Gala podría expresar, en lenguaje literario, buena parte de nuestro razonamiento: "los hombres nunca han dejado de adorar: lo que ocurre es que antes adoraban al becerro de oro y hoy adoran el oro del becerro". En cualquier caso, ni gobierno exclusivo de la racionalidad sobre los comportamientos e ideas, ni sociedad secularizada es lo que caracteriza a nuestro mundo contemporáneo, sino pluralidad de sacralidades y fragmentación del ámbito de lo sacro, aunque con el Mercado y sus leyes ocupando el espacio central de este e imponiendo o subsumiendo en su lógica la de los otros sacros. Es por ello que los gobiernos de los estados no son hoy capaces de controlar a las fuerzas del Mercado, sobre todo de capitales, y se pliegan a estas, legitimándolas y favoreciendo su expansión. Se ha verificado una inversión en la relación entre Estado y Mercado, entre ámbito político y esfera económica. Son las instancias de la globalización del Mercado —el Banco Mundial, el Fondo Monetario Internacional, la OMC, los bancos centrales- quienes gobiernan el mundo y definen el marco dentro del cual han de restringirse las decisiones políticas de los gobiernos.

Fue esta, también, la principal causa de la caída de los regímenes políticos del llamado "socialismo real", no basados en la economía de mercado. Y es lo que explica que en los países occidentales las religiones no sólo estén hoy también compitiendo entre sí y con las llamadas "sectas" dentro de un mercado espiritual - para lo cual, aunque en no pocos casos fortalezcan su interpretación integrista, utilizan abiertamente la mercadotecnia-, sino que dentro de ellas sea posible, para cada quién, aunque no sin enojo de las jerarquías, practicar una religiosidad parcialmente secularizada y subjetivista que se expresa en la

15. El Estado estuvo sacralizado — se constituyó como Absoluto y, en calidad de tal, se autolegitimó- desde su aparición, aunque para reproducirse y, a la vez, mantener opaca su verdadera naturaleza de hecho factual de poder, fundiera su sacralidad con la sacralidad religiosa. En la transición al capitalismo en Europa, la religión dejó de ser el eje central de la legitimación y reproducción del sistema económico, social y político, siendo desplazada de la centralidad de esta función - aunque no eliminada - por la nueva sacralidad de la Razón. Ello se produjo en el contexto de un fuerte proceso de laicismo, que inadecuadamente ha sido presentado como secularización. 
noción de "religión a la carta". A su vez, los fundamentalismos religiosos no occidentales tienen como vertiente principal la resistencia contra la imposición por parte de Occidente del Mercado como sacralidad única.

El proceso de homogeneización cultural era el tercero de los ejes o pilares sobre los cuales habría de avanzar obligatoriamente la Modernidad. En este sentido, es obvio que el colonialismo cultural, la acción de los grandes medios de propaganda (en la mayoría de los casos, mal denominados medios de comunicación) y las grandes migraciones desde la segunda mitad del siglo XIX hasta hoy, entre otros factores, han hecho posible el que en casi cualquier lugar del mundo, siempre que se posea la capacidad económica necesaria, puedan consumirse unos mismos productos, mantener un mismo confort $\mathrm{e}$ igual temperatura en las viviendas, vestir unos mismos pantalones de marca, escuchar la misma canción o tomar la misma bebida on the rocks. Y también que unos mismos espectáculos, musicales o deportivos, o un tipo de fast food gocen del interés y el favor de cientos de millones de personas, sobre todo jóvenes, con muy diferentes raíces culturales. Para no hablar de los programas que se repiten en las televisiones de los más diferentes países o de la imposición del inglés como lengua obligada en los foros internacionales y el mundo de las empresas. Todo ello es cierto, real, pero constituye sólo una parte de la realidad. Porque, además de esta dinámica, indudablemente uniformizadora - que nada, o bien poco, tiene que ver con la interculturalidad y sí mucho con el imperialismo cultural y con los intereses de las grandes compañías trasnacionales-, estamos asistiendo también al creciente protagonismo de la dinámica justamente contraria: cada día son más valoradas y utilizadas por sus hablantes las lenguas minoritarias, hay más participación activa en los rituales y fiestas de reproducción de las identidades culturales específicas, resurge la música y la alimentación "étnicas", y adquieren una fuerte carga simbólica viejos o nuevos símbolos de identidad y referentes de identificación de los pueblos y etnonaciones sin Estado y de los colectivos minorizados que se autodefinen a través del género, de la opción sexual, de la edad o de la religión. Y es que, junto al proceso indudable de uniformización cultural, funciona el no menos evidente proceso de reafirmación de las culturas específicas por los grupos identitarios que se definen a través de ellas ${ }^{16}$.

La uniformización, lejos de ser hoy la única tendencia sobre la que se sitúa la evolución

16. El estudio de las identidades colectivas, de sus condiciones de aparición y reproducción, y de los contenidos y mecanismos de la matriz estructural identitaria - que considero integrada por las identidades etnonacionales, las identidades de género y las identidades definidas a través de las culturas del trabajo-constituye, desde hace más de veinte años, el marco teórico-metodológico del grupo de investigación GEISA (Grupo para el Estudio de las Identidades Socioculturales en Andalucía) que dirijo en el Departamento de Antropología Social de la Universidad de Sevilla. Un primer intento de teorización fue publicado con el título de "Identidades y rituales. Estudio introductorio" en el libro colectivo del que fui coeditor, junto a los profesores Joan Prat, Jesús Contreras y Ubaldo Martínez, Antropología de los pueblos de España. Ed. Taurus, Madrid, 1991, pp. 601-636. 
de los modos de vida y las expresiones culturales de las diferentes sociedades y grupos humanos, no es sino una de las dos dimensiones, contradictorias pero igualmente ciertas, de nuestra realidad contemporánea. Aunque sea hoy, sin duda, la dinámica más potente, por ser la que mejor responde a la lógica del Mercado - y por ello ataca constantemente la diversidad o la exotiza, desactivándola de sus potencialidades identitarias y transformándola en mercancía-, su expansión se acompaña y confronta con el fortalecimiento de la dinámica contraria de reafirmación de las identidades colectivas $^{17}$. De aquí que, en lugar de admitir que la única dinámica actual sea la de la globalización mercantilista, debamos de entender nuestro mundo como resultado de la doble dinámica entre Globalización y Localización (o activación de lo identitario). El neologismo Glocalización, propuesto a finales de los ochenta por sociólogos británicos como Roland Robertson expresa esta doble e inseparable dinámica ${ }^{18}$.

El cuarto y último de los pilares o ejes sobre los que se construyeron los modelos e ideologías de la Modernidad también se ha mostrado muy frágil, por insuficientemente explicativo y porque, en ninguna de sus dos variantes, ha conducido a sociedades más justas, sostenibles y felices. En el interior de las construidas desde el paradigma liberalburgués del individualismo y la competitividad, ni todas las personas gozan realmente de los derechos que han sido definidos universalmente como Derechos Humanos, a pesar de que estos se hallen recogidos formalmente en las constituciones políticas "democráticas", ni los individuos son realmente libres para decidir sobre los asuntos colectivos, aunque sean definidos como ciudadanos $-\mathrm{y}$, por tanto como supuestamente libres para la toma de decisiones-, tanto por la insuficiencia de los cauces jurídico-políticos como

17. Moreno, I.: “Globalización, mercado, cultura e identidad”, en Entre las Gracias y el Molino Satánico. Lecturas de antropología económica. Paz Moreno Felíu (comp.), pp. 485-514. Universidad Nacional de Educación a Distancia, Madrid, 2004; “Globalizaciones y resistencias”. Mediodía. Desde el Mundo Mediterráneo, nº 0, 2004, pp. 31-35; “Globalización y cultura”, en J. Roche Cárcel y M. Oliver Narbona (eds.), Cultura y globalización. Entre el conflicto y el diálogo, pp. 65-88. Publicaciones Universidad de Alicante, 2005 y "Fundamentalismos globalizadores versus diversidad cultural”, en Juan Agudo Torrico (coord.), Culturas, poder y mercado. X Congreso de Antropología, pp. 37-58. Fundación El Monte, FAAEE y ASANA, Sevilla, 2005

18. El libro más influyente de Robertson ha sido Globalization: Social Theory and Global Culture. London, Sage, 1992. Otro autor de interés es M. Feathersone, autor de Global Culture: Nationalism, Globalization and Modernity, London, Sage, 1991 
por la presión de la ideología dominante y la publicidad ${ }^{19}$. A su vez, los movimientos sociopolíticos de los sectores sociales minorizados (movimientos etnonacionales, feministas, de minorías sexuales, religiosos, etc.) cobran fuerza creciente y exigen se reconozca la existencia no sólo de derechos individuales sino también de derechos colectivos. Dichas "minorías " plantean con fuerza su carácter de sujetos colectivos y no de simples problemas a resolver o a ignorar. Por su parte, en las sociedades socialistas (mejor, autodefinidas como socialistas), sólo la clase fue considerada como sujeto central de derechos. Por eso fueron tan escasamente respetados los derechos individuales, al ser contempladas las personas concretas como simples partículas de aquella, sin apenas significación en sí mismas y sólo consideradas en tanto su "posición de clase". Y por ello tampoco fueron reconocidos, más allá de vacías declaraciones retóricas, los derechos de los pueblos-naciones existentes en el interior de cada Estado o "unión de repúblicas". Ni los derechos de las mujeres como tales, ni de los homosexuales, ni de los colectivos religiosos...

No sucedió lo "previsto" desde las respectivas ideologías en el campo de la jerarquización social: ni se han atenuado las líneas de fractura social, mediante la pregonada movilidad social ascendente de "los mejores" - los más competitivos-, como afirmaban las teorías liberales, ni el conjunto de la sociedades del mundo se han polarizado en dos bloques nítidos, capitalistas versus proletarios, como señalaban las corrientes marxistas. Más bien, sobre todo en las sociedades occidentales, se está consolidando un funcionamiento que responde a una estructura tripartita, de tres bloques que no se corresponden a tres clases sociales, definidos principalmente por su posición estructural respecto no sólo a los medios de producción sino al acceso a los bienes y servicios sociales, especialmente al mercado de trabajo, y a las posibilidades de participación social. El primero de estos bloques es el de los integrados: aquellos que están incorporados al sistema, a "la sociedad", más allá de la clase social a la que objetiva o subjetivamente puedan pertenecer. En este bloque, sin duda heterogéneo, se incluyen colectivos pertenecientes a diferentes clases y estratos sociales, incluyendo las denominadas "clases medias" y la "clase obrera tradicional" (la caracterizada por tener un empleo fijo y acceso a los servicios conquistados por su lucha de más de un siglo). El segundo bloque es el de los precarios, en crecimiento constante debido al funcionamiento, cada día más salvaje, de las "leyes" del Mercado, con el deterioro consiguiente del llamado Estado del Bienestar,

19. Moreno, I.: "Derechos Humanos, ciudadanía e interculturalidad" En Emma Díaz y Sebastián de la Obra (eds.): Repensando la Ciudadanía, pp. 9-35. Fundación El Monte, Sevilla, 1999; "Mundialización, globalización y nacionalismos: la quiebra del modelo de Estado-nación”, en Carbonell, M. y Vázquez, R. (comp.): Estado constitucional y globalización, pp. 67-83. Ed. Porrúa-UNAM, México, 2001; “La 'segunda modernización' de Andalucía: discursos y prácticas del neoliberalismo en una sociedad de la periferia del centro", en VVAA, $L a$ globalización y los derechos humanos. IV Jornadas Internacionales de Derechos Humanos (Sevilla 2003), pp. 317-360. Talasa Ediciones y Asociación Pro Derechos Humanos de Andalucía, Madrid, 2004. 
allí donde lo hubo o se vivió un acercamiento a dicho modelo. Componen este bloque los trabajadores con empleos temporales o discontinuos, los prejubilados, los subsidiados de diverso tipo, los pensionistas, así como la mayor parte de los "autoempleados", todos ellos con muy graves problemas de inserción social y de acceso a los servicios públicos fundamentales. Y el tercer bloque, también cada vez más amplio, es el de los excluidos o marginalizados, el de quienes sufren la marginación en prácticamente todos los aspectos de la vida económica, social, política y cultural. Pertenecen a él sectores de población que cayeron primero en la precarización y luego en la marginación, junto a jóvenes que no encuentran posibilidades de integración laboral y social, a minorías étnicas y nacionales, y a un contingente cada vez mayor de inmigrantes procedentes de países del Sur a los cuales incluso se les niega la categoría legal de ciudadanos ${ }^{20}$. Por supuesto, la crisis actual está ampliando espectacularmente los bloques de precarios y marginalizados.

\section{DESARROLLO Y GLOBALIZACIÓN COMO FETICHES SUCESORES DE MODERNIDAD Y PROGRESO. LA SACRALIZACIÓN DE LA LÓGICA DE MERCADO.}

La quiebra de los cuatro pilares básicos de la Modernidad no podía menos que arrastrar en su caída a los discursos teórico-filosóficos y las construcciones políticas que se erigieron sobre ellos: el modeloliberal-burgués y el socialista-marxista. Con la casi total desaparición del segundo - el caso chino y algún otro son hoy una mezcla de neoliberalismo salvaje en lo económico y de dictadura de partido en lo político, mientras que el cubano representa un caso peculiar en el que sigue pesando más el antiimperialismo yanki que las ideas socialistas - no se consumó el triunfo del capitalismo neoliberal sin alternativa posible, ni se produjo el fin de la historia, tal como proclamaron los más fanáticos publicistas del sistema. Sólo la violencia social estructural, la violencia de la propaganda cultural (incluyendo en ella muchos estudios en ciencias sociales que naturalizan la desigualdad y esconden la insostenibilidad del sistema), el vaciamiento de las fórmulas democráticas y la proliferación de muros en las relaciones Norte-Sur mantienen hoy el espejismo de la supuesta vigencia de los pilares sobre los que sigue cimentándose el modelo de dominación imperante en el mundo.

En lugar deasumir quelos pilares sobrelos que se construyó el marco teórico-metodológico de la Modernidad no eran sólidos, y eran incapaces, por tanto, de sustentar modelo sociopolítico alguno que avanzara hacia la consecución de los objetivos afirmados en los discursos ilustrados, algunos defensores de la Modernidad, autodefinidos políticamente como progresistas - aunque el calificativo refiere a la idea dieciochesca de Progresooptaron por argumentar, como vimos hace Habermas, que el problema estriba en que la Modernidad se ha desplegado de forma parcial e insuficiente, por lo que habría que

20. Moreno, I.: o.c., 1999. 
seguir avanzando en ella rectificando sólo errores puntuales y algunas perversiones surgidas en su avance.

Otros, desde posiciones de firme defensa del modelo liberal-burgués, han optado por negar el problema, acudiendo al fetichismo de las palabras. Ahora, en lugar de Progreso se repite Desarrollo y en lugar de Modernidad se afirma Globalización, con lo que los mitos iniciales no sólo se mantienen sino que se naturalizan y sacralizan aun más: así, las leyes del Mercado y su carácter autorregulador, el beneficio económico y la propiedad privada como objetivo y estado natural de los seres humanos, la motivación utilitarista como única lógica racional, la superioridad de lo privado frente a lo público... Por ello, a la sacralización del Estado-Nación - verdadero "dios de la Modernidad”, en palabras de Llobera ${ }^{21}$ - ha sucedido la sacralización del propio Mercado, al que podría considerarse hoy como el verdadero "dios de la Globalización"22").

La evidencia, ya por todos reconocida, del carácter finito de los recursos y las consecuencias nefastas de la explotación intensiva de la naturaleza - sobre todo, el cambio climático que ya ha comenzado, pero también la especulación con las materias primas que acentúa la situación de hambre y pobreza en muchos lugares, la dedicación de alimentos para producir combustibles, las guerras por el control de territorios con reservas de recursos, etc. - no han conducido a un cuestionamiento del modelo económico sino al traslado de la creencia en el crecimiento indefinido desde el sector productivo de la economía (o economía "real") al sector financiero y especulativo (la pomposa denominada "nueva economía"). Así, la imposibilidad del mantenimiento de crecimientos espectaculares en los beneficios reportados por la producción de bienes y servicios se ha querido resolver por el espectacular crecimiento, demostrado posible durante dos décadas, de los beneficios obtenidos mediante operaciones financieras. Sin embargo, la actual crisis - cuyas consecuencias para los otros sectores de la economía están siendo devastadoras y aun no han terminado- demuestra con claridad que también existen límites para el incremento de los beneficios financieros: las "burbujas" no pueden hincharse indefinidamente, porque terminan estallando. ¿Dónde se refugiará, a partir de ahora, el mito del crecimiento indefinido?

La constatación de qué mundo ha creado la lógica de la Razón no ha sido motivo suficiente para desvelar con claridad el carácter clasista, sexista, racista y eurocéntrico de dicha lógica, que continúa siendo presentada como "natural", sino para subsumirla

21. Llobera, J.: The God of Modernity. The Development of Nationalism in Western Europe. Oxford, Berg, 1994 (Hay traducción española en Anagrama, Barcelona, 1996).

22. Moreno, I.: "El mercado como religión y el papel de las religiones bajo la hegemonía del sacro mercado", en Simona Scotti e María Eugenia Olavarría (eds.) La Natura e l'anima del mondo. Le fronteire della globalizzazione, pp. 109-125. Firenze: Mauro Pagliai Editore, 2009 y “Religiones, sacralidades laicas y 
en la lógica del Mercado; una lógica que no sólo gobierna la dimensión económica sino que trata de gobernar todas las dimensiones de la vida, colectiva e individual. Así, no sólo vivimos en una economía de mercado sino, cada día más, también en sociedades de mercado y en una cultura de mercado. La dinámica es la conversión tanto de los bienes producidos como de los servicios que responden a necesidades vitales, como los propios sentimientos, como las identidades, en otras tantas mercancías que compiten con otras de su mismo carácter en los diversos mercados. Y que son invertidas como capital, si la posición del sujeto es favorable y conviene a sus intereses: la amistad y las redes que podrían ser de solidaridad se convierten en "capital social" y el bagaje cultural e identitario en "capital simbólico". Por ello, cuanto no se considera útil para ser vendido como mercancía se descalifica o desprecia.

Desde esta lógica del Mercado, encaminada a la obtención del mayor beneficio (monetario y de éxito social en los diversos mercados en que ha sido transformada la vida colectiva) sin atender a los costes humanos, sociales y ecológicos, y definida como autorregulada, los enemigos a batir son el trabajo como categoría básica de la vida y derecho permanente, los mecanismos de redistribución y control por parte de las instituciones políticas, y la diversidad cultural productora de identidades colectivas. Y, por otra parte, desde ella se afirma la correspondencia e indisolubilidad entre los elementos de la triada central del discurso ideológico de la globalización capitalista: el Mercado "libre", la Democracia y los Derechos Humanos. Pero, no nos engañemos, cuando se habla de Mercado libre se está defendiendo la ley de la selva y el darwinismo social en las relaciones económicas y se está rechazando, por definición, cualquier regulación o intervención exterior al mercado mismo, es decir a las grandes instituciones que gobiernan la economía del mundo -FMI, BM, Banco Central Europeo, OMC - y a las entidades financieras y a las trasnacionales ${ }^{23}$, con lo que se sustrae la economía de la política, impidiendo cualquier control o participación democrática en la misma. Por democracia política hay que entender simplemente existencia de elecciones con más de una papeleta y no participación real y consciente de los ciudadanos en las decisiones sobre los asuntos públicos. La esfera política ha sido vaciada de la mayor parte de su contenido al haber salido de ella gran parte de los competencias sobre el ámbito económico, los ciudadanos han sido transformados, con la ayuda del marketing electoral, en meros consumidores de votos y los partidos han pasado a ser maquinarias electorales desideologizadas salvo para discursos oportunistas puntuales, con lo que las propias elecciones se han convertido en rituales casi vacíos de contenido real -la mayoría de las opciones electorales con alguna posibilidad de éxito

23. Salvo en ocasiones de emergencia, en que sí se acude al Estado para que este, con los fondos de los impuestos que pagamos los ciudadanos enjugue el déficit de grandes empresas o, como ahora, impida el hundimiento de corporaciones financieras, pero sin que ello suponga aceptación de derecho alguno de intervención controladora. 
son ramas del mismo tronco neoliberal- pero que legitiman el propio sistema de no participación real. Y en cuanto a los Derechos Humanos, han llegado incluso a ser, como la "extensión de la Democracia", una excusa para tratar de legitimar invasiones militares con objetivos claramente económicos o geoestratégicos. El discurso de los Derechos Humanos presente en la triada supone también una manipulación descarada de estos, en tanto que se consideran sólo los derechos individuales y no los colectivos, únicamente —cuando más- los cívicos y no los económico-sociales ni los culturales, y, además, son objeto de violaciones constantes desde el poder, si dificultan el cumplimiento de las "leyes" del libre Mercado o por "razones" de Estado, y de suspensiones temporales o permanentes para toda la población o para sectores de esta - la negación de los inmigrantes irregulares como sujetos de derechos es uno de los ejemplos más escandalosos-.

Y se repite continuamente que no existe, y ni siquiera es pensable, posibilidad alguna de alternativa al sistema. La naturalización de este, su afirmación como único modelo universal que responde a la Razón, que es compatible con la Democracia y los Derechos Humanos y que conduce al Desarrollo - calificado ahora como "sostenible", "endógeno", "ecodesarrollo", "co-desarrollo", etc., en un sinfín de términos que funcionan sólo a modo de jaculatorias-, lo convierten en pensamiento único supuestamente incuestionable. La mayor parte de los considerados científicos sociales - en primer lugar los economistas pero también sociólogos, antropólogos, politólogos y profesionales de otras disciplinashan tenido y tienen un destacado papel en esta naturalización y en la consiguiente conversión del Mercado y su lógica en el sacro central de nuestro mundo.

\section{LAS OPCIONES ACTUALES DE LA ANTROPOLOGÍA.}

En este contexto, heredero directo del pensamiento ilustrado que se despliega en los eslabones del Progreso-Modernización-Desarrollo-Globalización, ¿cuáles son los papeles posibles de una Antropología que no responda a este pensamiento único y que, por ello, no esté totalmente colonizada y al servicio de los poderes dominantes? De una Antropología que no sea reflejo de la subalternidad respecto a los centros de poder académico hegemónico.

La primera opción es aceptar, explícita o implícitamente, como pensamiento único revestido de respetable cientificidad el que se nos presenta como tal desde los centros de poder académico del Norte. Insertarse en la lógica sacralizada del Mercado, en una situación de marcada subalternidad y formar parte de redes clientelares dependientes. Es esta opción la que siguen muchos académicos, también del Sur, y está respaldada por las políticas educativas de los gobiernos neoliberales - que a veces continúan autodenominándose socialdemócratas- tanto del Sur como del Norte. Todas las reformas del llamado "proceso de Bolonia" en Europa no son otra cosa que la aceleración de la adaptación de las estructuras y contenidos de las universidades a la lógica globalizadora del Mercado y su pensamiento único. En este contexto, la investigación es orientada hacia 
cuestiones desligadas de los problemas de las mayorías sociales o que son periféricas, y se evita - vía recorte de subvenciones, por ejemplo - el estudio de los mecanismos de reproducción de desigualdades. Es esta una opción que acentúa la situación de colonización intelectual de la Antropología, anula su potencialidad crítica y la convierte en instrumento de aceptación del orden económico y sociopolítico.

La segunda opción parte de la crítica al monopolio del conocimiento y la teoría antropológica por parte de los antropólogos del Norte - que es parte del imperialismo cultural existente - y de la situación de "asimetría estructural" entre aquellos y los antropólogos del Sur. La solución del problema pasaría, como apunta por ejemplo Llobera, por la creación de medios de difusión antropológica de nivel internacional en países no centrales, con utilización del idioma inglés para facilitar ser leídos en el Norte - o al menos esa sería la esperanza - y con la colaboración de aquellos antropólogos del Norte que se presten a ser cauces para dar a conocer los productos intelectuales del Sur ${ }^{24}$. Pienso al respecto que, como el objetivo sería incorporarse a la "comunidad antropológica internacional", dominada por quienes actúan en los centros de poder hegemónicos, es difícil imaginar que esta incorporación pueda hacerse, salvo en casos muy concretos, en una posición distinta a la subalternidad o el clientelismo.

La tercera opción, que es la que aquí defendemos, es la de un desarrollo autónomo que no autista- de las Antropologías del Sur con el común objetivo de desvelar los mecanismos estructurales y simbólicos de producción y reproducción de desigualdades que conforman la dominación de clase, de género y étnica en los diversos contextos - mundial, nacionales y locales - e implicarse en la defensa de la diversidad cultural y de los derechos culturales colectivos para construir sociedades más justas e integradas, abiertas a la interculturalidad.

En este empeño, que no puede ser sólo de los antropólogos/as, la Antropología puede ofrecer, por su tradición comparativista y sus herramientas metodológicas, un bagaje especialmente útil para la desnaturalización y desacralización de la lógica dominante y de sus producciones. El objetivo sería dar cuenta de la posibilidad real de un mundo verdaderamente secularizado (y no sólo laico), es decir, un mundo sin sacros o Absolutos Sociales incuestionables ni leyes o razones por encima de las necesidades y aspiraciones humanas. Un mundo que pueda avanzar hacia la igualdad de derechos y posibilidades tanto para los individuos como para los colectivos sociales y los pueblos, dentro del cual sean posibles muchos mundos, es decir, formas diferentes de organizar, vivir e interpretar la experiencia humana, en un marco de mutuo reconocimiento y de respeto a los derechos colectivos e individuales de la humanidad, definidos estos de forma intercultural.

Para ello, considero que no basta con un ejercicio de voluntad de descolonización,

24. Llobera, J.: o. c., 1990. 
siendo ello imprescindible, sino que es necesario alejarse no sólo del contenido y de la propia lógica de los modelos construidos a partir del pensamiento ilustrado - es decir, en base a la lógica del progreso, de la modernización, del desarrollo y de la globalización como etapas sucesivas supuestamente "naturales" - sino también de las formas mismas de operar nuestra mente que dicho pensamiento ha generado. Dos ejemplos podrían explicar más claramente a lo que me refiero.

El primero refiere a la forma de resolución de un problema, de cualquier problema. La lógica racionalista nos ha llevado a la creencia de que un problema tiene una única solución correcta o, si se quiere, una única solución óptima. Siempre habrá una solución demostradamente más racional, eficiente y democrática que cualquier otra, válida universalmente. La Antropología debe desmitificar esta creencia equivocada, mostrando que han existido y existen diversas fórmulas para enfrentarse a unas mismas necesidades y problemas; fórmulas que responden a diversas lógicas y valores, y que no están situadas en una jerarquía de superioridad-inferioridad ni en una escala abstracta de nivel de eficiencia, porque la propia eficiencia se define culturalmente y no mediante una ecuación matemática. No creo necesario señalar la importancia de esta demostración para la desnaturalización y desacralización de los modelos occidentales construidos como presuntamente universales.

El segundo ejemplo refiere al imprescindible cuestionamiento de otra supuesta verdad, también herencia del pensamiento ilustrado y que ahora se refleja en una frase mil veces repetida y supuestamente correcta para orientar la práctica política dicha progresista. Es la de "pensar globalmente y actuar localmente". Creo imprescindible deconstruir la aparente obviedad de esta fórmula con pretendida validez general. Se hace necesario liberar nuestro pensamiento de un dogma que es presentado como simple "sentido común": el que afirma que lo mayor es superior a lo menor, lo grande a lo pequeño, y que lo local es simplemente lo global a escala reducida. Más en concreto, la frase anterior refleja precisamente las estrategias de poder de las corporaciones trasnacionales, hoy, $\mathrm{y}$ de las instituciones que, tanto hoy como en el pasado, han tratado de gobernar el mundo en nombre de los diferentes sacros: religioso, político y ahora mercantil, cuyas lógicas han aspirado a globalizarse, es decir, a gobernar sobre todos los territorios y pueblos del planeta y en todas las dimensiones y ámbitos de la vida social. La frase en cuestión afirma implícitamente que la mirada y los intereses globales son superiores y prioritarios respecto a los intereses y las miradas locales y sectoriales. No considera la posibilidad de que la supuesta perspectiva global sea la de un local que, ejerciendo su hegemonía, se autodefina como global, que es lo que realmente ha sucedido con el local euro-norteamericano que se presenta hoy como supuestamente global, como universal. Desde esta perspectiva, lo local - sea a nivel territorial, sectorial o identitario- sería solamente el escenario concreto de actuación de los poderes e intereses globales, el lugar 
donde estos han de activarse, adaptando si fuera necesario algún elemento secundario a las peculiaridades de cada caso para penetrar mejor.

Frente al paradigma de la prioridad de lo global sobre lo local, que es el paradigma de la globalización del Mercado y de todas las globalizaciones anteriores, hay que oponer como paradigma - rechazando también la posición localista que contempla la totalidad sólo a través del ojo de una cerradura- el de "pensar y actuar glocalmente", es decir, teniendo a la vez en cuenta las consideraciones, análisis e intereses generales y las perspectivas e intereses locales. Porque, en realidad, incluso lo que afecta globalmente al planeta y a la humanidad entera tiene efectos diferenciales en los diferentes territorios y en los diversos pueblos y sectores sociales.

Son estos dos paradigmas, el de "pensar y actuar glocalmente" y el de partir de que "un mismo problema puede tener diferentes soluciones", los que deberían caracterizar, hoy, a las diversas Antropologías del Sur para que estas avancen en su descolonización epistemológica y metodológica, y no sean meras sucursales académicas de los centros de poder académico de la globalización del Mercado, ni se conviertan en islas localistas ensimismadas, sin conexión entre sí y sin tender puentes a los antropólogos/as que en el Norte adoptan también, aunque minoritariamente, dichos paradigmas. Que los hay, crecientemente, sobre todo en sus periferias internas.

De la expansión de estos paradigmas y del establecimiento de estas conexiones y complicidades en pie de igualdad es de donde podría surgir el necesario, y urgente, replanteamiento de la disciplina que convierta a esta en una vía de conocimiento riguroso y crítico y en un instrumento de resistencia frente a todas las globalizaciones y al servicio de la comprensión y solución de los problemas humanos. 